University of Nebraska - Lincoln

DigitalCommons@University of Nebraska - Lincoln

Faculty Publications from the Department of Electrical \& Computer Engineering, Department Electrical and Computer Engineering

$11-14-2004$

\title{
Annealing and oxidation of silicon oxide films prepared by plasma-enhanced chemical vapor deposition
}

\author{
X. Y. Chen \\ National University of Singapore \\ Yongfeng Lu \\ University of Nebraska-Lincoln, ylu2@unl.edu \\ L. J. Tang \\ Institute of Microelectronics, 11 Science Park Road, Singapore 117685, Singapore \\ Y. H. Wu \\ National University of Singapore \\ B. J. Cho \\ National University of Singapore \\ See next page for additional authors
}

Follow this and additional works at: https://digitalcommons.unl.edu/electricalengineeringfacpub

Part of the Electrical and Computer Engineering Commons

Chen, X. Y.; Lu, Yongfeng; Tang, L. J.; Wu, Y. H.; Cho, B. J.; Dong, J. R.; and Song, W. D., "Annealing and oxidation of silicon oxide films prepared by plasma-enhanced chemical vapor deposition" (2004). Faculty Publications from the Department of Electrical and Computer Engineering. 92.

https://digitalcommons.unl.edu/electricalengineeringfacpub/92

This Article is brought to you for free and open access by the Electrical \& Computer Engineering, Department of at DigitalCommons@University of Nebraska - Lincoln. It has been accepted for inclusion in Faculty Publications from the Department of Electrical and Computer Engineering by an authorized administrator of DigitalCommons@University of Nebraska - Lincoln. 


\section{Authors}

X. Y. Chen, Yongfeng Lu, L. J. Tang, Y. H. Wu, B. J. Cho, J. R. Dong, and W. D. Song 


\title{
Annealing and oxidation of silicon oxide films prepared by plasma-enhanced chemical vapor deposition
}

\author{
X. Y. Chen \\ Department of Electrical and Computer Engineering, National University of Singapore, \\ 10 Kent Ridge Crescent, Singapore 119260, Singapore \\ Y. F. Lu ${ }^{\mathrm{a})}$ \\ Department of Electrical Engineering, University of Nebraska, Lincoln, Nebraska 68588-0511 \\ L. J. Tang \\ Institute of Microelectronics, 11 Science Park Road, Singapore 117685, Singapore \\ Y. H. Wu, B. J. Cho, and X. J. Xu \\ Department of Electrical and Computer Engineering, National University of Singapore, \\ 10 Kent Ridge Crescent, Singapore 119260, Singapore \\ J. R. Dong \\ Institute of Materials Research and Engineering, 3 Research Link, Singapore 117602, Singapore \\ W. D. Song \\ Data Storage Institute, 5 Engineering Drive 1, Singapore 117608, Singapore
}

(Received 13 September 2004; accepted 13 October 2004; published online 16 December 2004)

We have investigated phase separation, silicon nanocrystal ( $\mathrm{Si} \mathrm{NC}$ ) formation and optical properties of $\mathrm{Si}$ oxide $\left(\mathrm{SiO}_{x}, 0<x<2\right)$ films by high-vacuum annealing and dry oxidation. The $\mathrm{SiO}_{x}$ films were deposited by plasma-enhanced chemical vapor deposition at different nitrous-oxide/silane flow ratios. The physical and optical properties of the $\mathrm{SiO}_{x}$ films were studied as a result of high-vacuum annealing and thermal oxidation. X-ray photoelectron spectroscopy (XPS) reveals that the as-deposited films have a random-bonding or continuous-random-network structure with different oxidation states. After annealing at temperatures above $1000{ }^{\circ} \mathrm{C}$, the intermediate $\mathrm{Si}$ continuum in XPS spectra (referring to the suboxide) split to $\mathrm{Si}$ peaks corresponding to $\mathrm{SiO}_{2}$ and elemental Si. This change indicates the phase separation of the $\mathrm{SiO}_{x}$ into more stable $\mathrm{SiO}_{2}$ and $\mathrm{Si}$ clusters. Raman, high-resolution transmission electron microscopy and optical absorption confirmed the phase separation and the formation of Si NCs in the films. The size of Si NCs increases with increasing $\mathrm{Si}$ concentration in the films and increasing annealing temperature. Two photoluminescence (PL) bands were observed in the films after annealing. The ultraviolet (UV)-range PL with a peak fixed at 370-380 nm is independent of Si concentration and annealing temperature, which is a characteristic of defect states. Strong PL in red range shows redshifts from $\sim 600$ to $900 \mathrm{~nm}$ with increasing Si concentration and annealing temperature, which supports the quantum confinement model. After oxidation of the high-temperature annealed films, the UV PL was almost quenched while the red PL shows continuous blueshifts with increasing oxidation time. The different oxidation behaviors further relate the UV PL to the defect states and the red PL to the recombination of quantum-confined excitions. () 2005 American Institute of Physics. [DOI: $10.1063 / 1.1829789]$

\section{INTRODUCTION}

Bulk silicon ( $\mathrm{Si}$ ) has an indirect band gap and is inefficient as a light source for optoelectronic applications. Ever since visible photoluminescence (PL) was observed in $\mathrm{Si}$ nanostructures, ${ }^{1-3}$ Si nanocrystals (NCs) have attracted great interest in microelectronics and optoelectronics for new opportunities to realize desirable Si-based light emitting devices (LEDs) which are compatible with current electronic ultralarge-scale-integration (ULSI) technologies. Among the Si nanostructures, porous Si (PS) with strong PL formed by electrochemical anodization of crystalline $(c-) \mathrm{Si}$ in hydro-

\footnotetext{
${ }^{a)}$ Author to whom correspondence should be addressed; electronic mail: yflu@engr.unl.edu
}

fluoric acid has been extensively studied. However, the PL from the PS is greatly dependent on the preparation conditions and degrades strongly in the environment. The fragile mechanical properties and inhomogeneous structure are also big concerns for the practical applications of the PS. Recently, much attention has been paid to the "dry" methods, such as chemical vapor deposition and physical vapor deposition, to form $\mathrm{Si} \mathrm{NCs}$. As $\mathrm{Si}$ is easily oxidized, the asdeposited Si NCs often show stoichiometries of Si suboxide due to the strong reaction of $\mathrm{Si}$ with residual oxygen during the deposition. In addition, "fresh" samples oxidize in air in seconds, changing the recombination mechanism and optical properties of the as-deposited $\mathrm{Si} \mathrm{NCs}$ to oxygen-related ones. ${ }^{4}$ Furthermore, $\mathrm{Si}$ oxide $\left(\mathrm{SiO}_{x}, 0<x<2\right)$ is a robust 
host that provides good passivation for $\mathrm{Si} \mathrm{NCs} \mathrm{SiO}_{x}$ embedded with Si NCs shows strong and stable PL, robust structure, and compatibility with microelectronic technology. Thus $\mathrm{SiO}_{x}$ is considered to be a practical and promising material for Si-based LEDs. $\mathrm{SiO}_{x}$ embedded with $\mathrm{Si} \mathrm{NCs}$ has been synthesized by several techniques, such as ion implantation of $\mathrm{Si}^{+}$into $\mathrm{Si}$ dioxide $\left(\mathrm{SiO}_{2}\right)$ films, ${ }^{5}$ cosputtering of $\mathrm{Si}$ and $\mathrm{SiO}_{2},{ }^{6}$ evaporation of $\mathrm{Si}$ monoxide $(\mathrm{SiO}){ }^{7}$ pulsed laser deposition (PLD) of $\mathrm{Si}$ in oxygen $\left(\mathrm{O}_{2}\right)$ gas, ${ }^{8}$ and plasmaenhanced chemical vapor deposition (PECVD) of $\mathrm{SiO}_{x}{ }^{9}{ }^{9}$ The ability to control the size distribution and surface condition of Si NCs with reproducibility is critical due to the sensitive light emitting properties of Si NCs. Among the various deposition methods for $\mathrm{SiO}_{x}, \mathrm{PECVD}$ and its other versions have been extensively utilized in the industry. Desired properties, such as good adhesion, low pinhole density, good step coverage, and adequate electrical properties, have made PECVD films useful in ULSI circuits. The characteristics of the $\mathrm{SiO}_{x}$ films deposited by PECVD can be finely tuned through the stoichiometry by varying flow ratios of the $\mathrm{Si} / \mathrm{O}$ species.

For the visible luminescence properties of Si NCs, the size distribution and surface condition of Si NCs play primary roles. Annealing and oxidation can greatly influence the size distribution of Si NCs. It is well known that hightemperature process will induce the formation of Si NCs in the as-deposited $\mathrm{SiO}_{x}{ }^{9,10} \mathrm{SiO}_{x}$ starts to separate into more stable $\mathrm{SiO}_{2}$ phase and $\mathrm{Si}$ clusters at the temperature range of 400-700 ${ }^{\circ} \mathrm{C}$ through the following equation: ${ }^{7,11,12}$

$$
\mathrm{SiO}_{x} \rightarrow \frac{x}{2} \mathrm{SiO}_{2}+\left(1-\frac{x}{2}\right) \mathrm{Si} .
$$

Oxidation will reduce the NC size by converting the outer layer of Si NCs into oxide. Furthermore, annealing and oxidation can greatly influence the surface condition of Si NCs. The high-density defects in the nonstoichiometric Si oxide matrix and interfacial layer of $\mathrm{Si} \mathrm{NCs}$ will be reduced by annealing and oxidation.

In this work, we studied the annealing and oxidation behaviors of the $\mathrm{SiO}_{x}$ films deposited by PECVD. The purpose of this work is to study the effects of thermal treatment on the structures and optical properties of Si NCs.

\section{EXPERIMENTAL SETUP}

$\mathrm{SiO}_{x}$ films were deposited on $\mathrm{Si}(100)$ or fused quartz substrates in an Oxford PECVD system using rf (13.56 $\mathrm{MHz}$ ) glow-discharge decomposition of very large scale integration (VLSI) grade $5 \% \mathrm{SiH}_{4}$ in nitrogen $\left(\mathrm{N}_{2}\right)$ carrier gas and VLSI grade $100 \%$ nitrous oxide $\left(\mathrm{N}_{2} \mathrm{O}\right)$. The chamber pressure, rf power, total flow rate, substrate temperature, and deposition time were kept at 1 Torr, $20 \mathrm{~W}, 880 \mathrm{sccm}, 300{ }^{\circ} \mathrm{C}$, and 5 min, respectively. The flow ratio $R=\left[\mathrm{N}_{2} \mathrm{O}\right] /\left[\mathrm{SiH}_{4}\right]$ was varied from 68 to 1 . The thickness of the films was about $300-500 \mathrm{~nm}$ as measured by surface profiling.

After deposition, annealing and oxidation were applied to the as-deposited films. Annealing was carried out ex situ in a high vacuum of $10^{-7}$ Torr for $60 \mathrm{~min}$ at temperatures ranging from 400 to $1200{ }^{\circ} \mathrm{C}$. Dry oxidation was carried out ex situ in a constant $\mathrm{O}_{2}$ (purity 99.7\%) gas flow at a temperature of either 1000 or $1200{ }^{\circ} \mathrm{C}$.

The surface composition of the films was determined by x-ray photoelectron spectroscopy (XPS) with a Physical Electronics Quantum 2000 Scanning electron spectroscopy for chemical analysis microprobe using a monochromatic Al $K_{\alpha}$ (energy $1486.6 \mathrm{eV}$ ) radiation. Spectra were taken after 2 min sputter etching to remove surface contamination. The energies of XPS spectra were calibrated using the C $1 s$ peak at a binding energy of $284.5 \mathrm{eV}$. Integrated peak area intensities under $\mathrm{O} 1 s, \mathrm{Si} 2 p$, and $\mathrm{N} 1 s$ peaks were used for estimating the relative elemental composition of the films after correction of core level atomic sensitivity factors.

The Raman spectroscopy was carried out using a Renishaw Micro-Raman microscope (spatial resolution: $\sim 1 \mu \mathrm{m}$ ) with an electrically cooled charge coupled device detector at room temperature, with a $514.5 \mathrm{~nm}$ Ar ion laser line as excitation source. The optical absorption was measured by a Shimadzu UV-3101PC spectrophotometer. The nanostructural features were observed by cross-sectional highresolution transmission electron microscopy (HRTEM) using a Philips CM200 FEG-TEM operated at $200 \mathrm{kV}$. The PL spectra were recorded by an Accent PL rapid mapping system (spatial resolution: $\sim 100 \mu \mathrm{m}$ ) using $325 \mathrm{~nm} \mathrm{He}-\mathrm{Cd}$ laser line $(3 \mathrm{~mW})$ and $532 \mathrm{~nm}$ Ar ion laser line $(10 \mathrm{~mW})$ as excitation sources. For Raman spectroscopy and optical absorption, samples deposited on quartz substrates were used.

\section{RESULTS AND DISCUSSION}

\section{A. Surface composition}

The surface composition of the $\mathrm{SiO}_{x}$ films before and after annealing was characterized by XPS. It is now widely accepted that the $\mathrm{Si} 2 p$ spectra can be interpreted in terms of five oxidation states $\mathrm{Si}^{0}, \mathrm{Si}^{1+}, \mathrm{Si}^{2+}, \mathrm{Si}^{3+}$, and $\mathrm{Si}^{4+}$. The network of $\mathrm{SiO}_{x}$ is formed by $\mathrm{Si}-\left(\mathrm{Si}_{4-n}-\mathrm{O}_{n}\right)$ tetrahedras with $n=0-4$. From pure amorphous $\mathrm{Si}(a-\mathrm{Si}, n=0)$ for $\mathrm{Si}$ atom bonded to four adjacent $\mathrm{Si}$ atoms to $a-\mathrm{SiO}_{2}(n=4)$ for $\mathrm{Si}$ atom bonded to four adjacent oxygen atoms, the adjacent $\mathrm{Si}$ atoms are stepwise replaced by oxygen atoms with increasing oxidation states. The increasing electronegativity of the $\mathrm{Si}-\mathrm{O}$ bond relative to the $\mathrm{Si}-\mathrm{Si}$ bond results in a shift to higher binding energy of the core-level electrons in $\mathrm{Si}$ atoms. The binding energies for the progression of $\mathrm{Si}^{0}$ to $\mathrm{Si}^{4+}$ range from approximately 99.3 to $103.3 \mathrm{eV}$ with a shift of $\sim 1 \mathrm{eV}$ per Si-O bond. ${ }^{13-15}$

Figure 1 shows the $\mathrm{Si} 2 p$ peaks in XPS spectra of the as-deposited $\mathrm{SiO}_{x}$ films. At the flow ratio $R=\left[\mathrm{N}_{2} \mathrm{O}\right] /\left[\mathrm{SiH}_{4}\right]$ ranging from 68 to 16.5 , the symmetrical peak at $103.2 \mathrm{eV}$ corresponding to $\mathrm{Si}^{4+}$ in $\mathrm{SiO}_{2}$ indicates that almost stoichiometric $\mathrm{SiO}_{2}$ films were obtained. With the flow ratio $R$ decreasing from 16.5 , Si $2 p$ peaks display asymmetrical broad peaks which are continually shifted to a lower binding energy. The Si concentration in the films is found to increase accordingly. At the flow ratio $R$ of 1 , the broad peak at 99.8 $\mathrm{eV}$ reflects the high $\mathrm{Si}$ concentration in the film. The progressively shifted broad and smooth $\mathrm{Si} 2 p$ peaks, composed of a superposition of different oxidation states, demonstrate that the as-deposited films have random-bonding or continuous- 


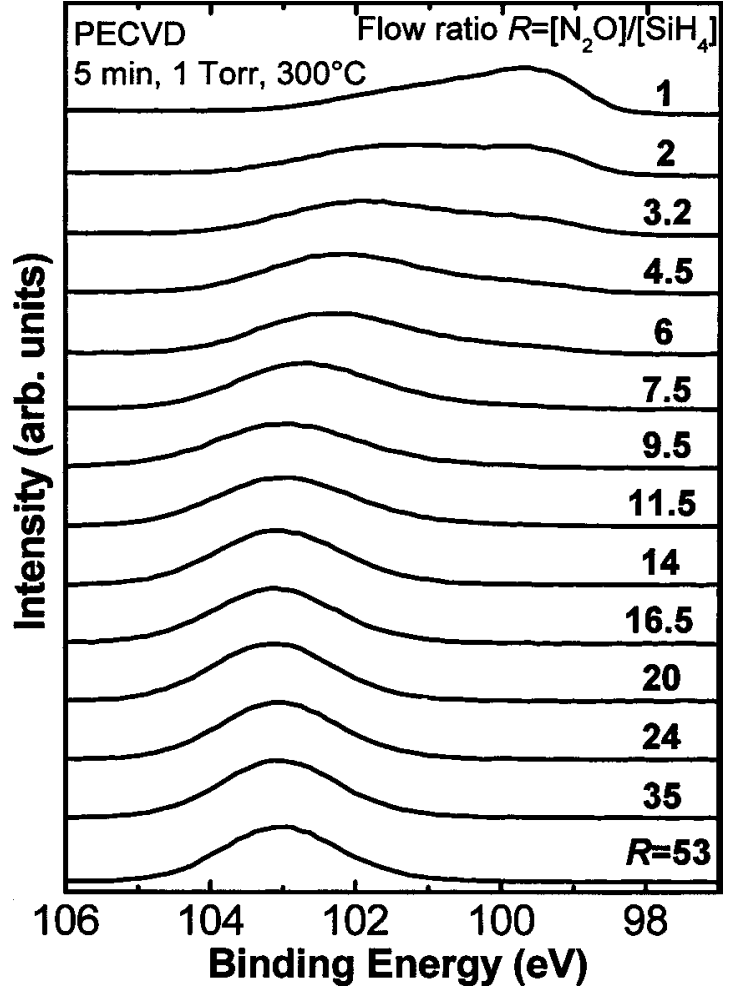

FIG. 1 . Si $2 p$ peaks in XPS spectra of the $\mathrm{SiO}_{x}$ films deposited at different flow ratios defined as $R=\left[\mathrm{N}_{2} \mathrm{O}\right] /\left[\mathrm{SiH}_{4}\right]$.

random-network structures. The large compositions of the $\mathrm{Si}^{1+}, \mathrm{Si}^{2+}$, and $\mathrm{Si}^{3+}$ components indicate the large amount of the suboxide in the films. Based on the Si concentration in the films, we may divide the flow ratio $R$ into three regimes: the high flow-ratio regime $H$, with the flow ratio $R$ ranging from 68 to 16.5 , corresponds to the as-deposited films with $\mathrm{SiO}_{2}$-like structures. The middle flow-ratio regime $M(R$ from 14 to 6) corresponds to the films with intermediate $\mathrm{Si}$ concentrations. The low flow-ratio regime $L$ (with $R$ from 4.5 to 1) corresponds to the films with high Si concentrations.

It should be pointed out that the as-deposited films are not pure $\mathrm{SiO}_{x}$ but contain nitrogen and hydrogen. The nitrogen needs to be taken into account for analyzing the film structures as it can replace the oxygen atom in the $\mathrm{Si}$ $\left(\mathrm{Si}_{4-n}-\mathrm{O}_{n}\right)$ tetrahedra structures. When the flow ratio $R$ is in the regimes $H$ and $M$, the nitrogen concentration in the films was found to be lower than 3 at. \%. As only the films deposited in the regimes $H$ and $M$ show strong PL after annealing, the influence of the low-concentration nitrogen is weaker.

Although the XPS study from Augustine et al. ${ }^{15}$ indicated that the phase separation of $\mathrm{SiO}_{x}$ does not occur even after annealing at $1050{ }^{\circ} \mathrm{C}$ for $30 \mathrm{~min}$, it is generally agreed that the phase separation starts at a temperature of 400 $700{ }^{\circ} \mathrm{C}$. Furthermore, obvious phase separation and formation of $c$-Si NCs have been observed by Fourier-transform infrared spectroscopy and TEM at a temperature of $900-1000{ }^{\circ} \mathrm{C}^{7,9,11,12}$ We studied the phase separation of the $\mathrm{SiO}_{x}$ films by thermal annealing in a vacuum. The asdeposited films become darker after annealing with increasing annealing temperature. Figure 2 shows the $\mathrm{Si} 2 p$ peaks in

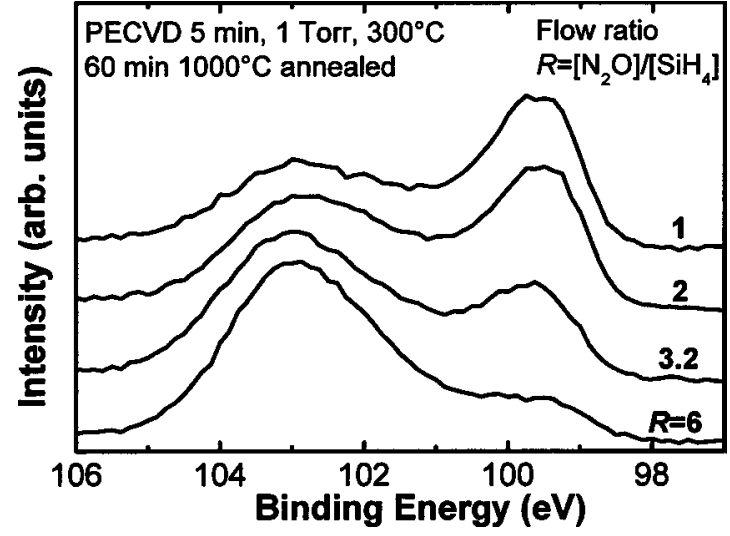

FIG. 2. Si $2 p$ peaks in XPS spectra of the $\mathrm{SiO}_{x}$ films after high-vacuum annealing for $60 \mathrm{~min}$ at $1000{ }^{\circ} \mathrm{C}$.

XPS spectra of the $\mathrm{SiO}_{x}$ films after annealing for $60 \mathrm{~min}$ at $1000^{\circ} \mathrm{C}$. After annealing, broad and smooth Si peaks for the as-deposited $\mathrm{SiO}_{x}$ films split to $\mathrm{Si}$ peaks of 103.0 and 99.5 $\mathrm{eV}$ with enhanced intensities. The contributions of the intermediate $\mathrm{Si}$ peaks $\left(\mathrm{Si}^{1+}, \mathrm{Si}^{2+}, \mathrm{Si}^{3+}\right)$ corresponding to the suboxide phases become smaller while $\mathrm{Si}^{4+}$ peak for $\mathrm{SiO}_{2}$ and $\mathrm{Si}^{0}$ peak for elemental $\mathrm{Si}$ are dominant. This observation indicates that the unstable suboxides have separated into two more stable $\mathrm{Si}_{-} \mathrm{Si}_{4}$ and $\mathrm{Si}-\mathrm{O}_{4}$ tetrahedras. Thus, there is a clear phase seperation of the $\mathrm{SiO}_{x}$ films after annealing at $1000{ }^{\circ} \mathrm{C}$.

\section{B. Raman spectra}

The phase separation of the $\mathrm{SiO}_{x}$ films was further studied by Raman spectroscopy. Figure 3(a) shows the Raman spectra of the as-deposited $\mathrm{SiO}_{x}$ films. The Raman spectrum of the $c$ - $\mathrm{Si}(100)$ substrate is also presented as a reference. As shown in Fig. 3(a), at a flow ratio $R$ higher than 7.5, the as-deposited films show a featureless background without any peaks. With decreasing flow ratio $R$ from 7.5, a broadband at $\sim 480 \mathrm{~cm}^{-1}$ appears with increasing intensity. The broadband corresponds to the $a$-Si, suggesting the existence of the $a$-Si phase. It is reasonable that $a$-Si exists in the films due to the introduced $\mathrm{Si}-\mathrm{Si}$ bond states when the $\mathrm{Si}$ concentration is high.

Figure 3(b) shows the Raman spectra of the $\mathrm{SiO}_{x}$ films after high-vacuum annealing for $60 \mathrm{~min}$ at $1000{ }^{\circ} \mathrm{C}$. The $a$-Si band at $\sim 480 \mathrm{~cm}^{-1}$ is greatly enhanced after annealing. In addition, a broad peak at $513-518 \mathrm{~cm}^{-1}$ corresponding to the $c$-Si shows increased intensity with decreasing flow ratio $R$. The existence of the broad $a$-Si band after annealing at $1000{ }^{\circ} \mathrm{C}$ suggests that the $\mathrm{SiO}_{x}$ films have a higher recrystallization temperature than the recrystallization temperature of $a$-Si film at $\sim 600^{\circ} \mathrm{C}$. The broad crystalline peak proves the presence of $c$-Si NCs in the films. From the enhancement of the $a$-Si phase and the formation of $c$-Si NCs, the phase separation of the $\mathrm{SiO}_{x}$ films after annealing at $1000{ }^{\circ} \mathrm{C}$ can be confirmed. It is also noticed that the crystalline peak of the $\mathrm{SiO}_{x}$ films is redshifted and broadened compared to the Raman signature of the $c$-Si substrate, which may be related to the phonon confinement effects. ${ }^{16}$ However, a quantitative analysis of the NC size by the phonon confinement effects is 

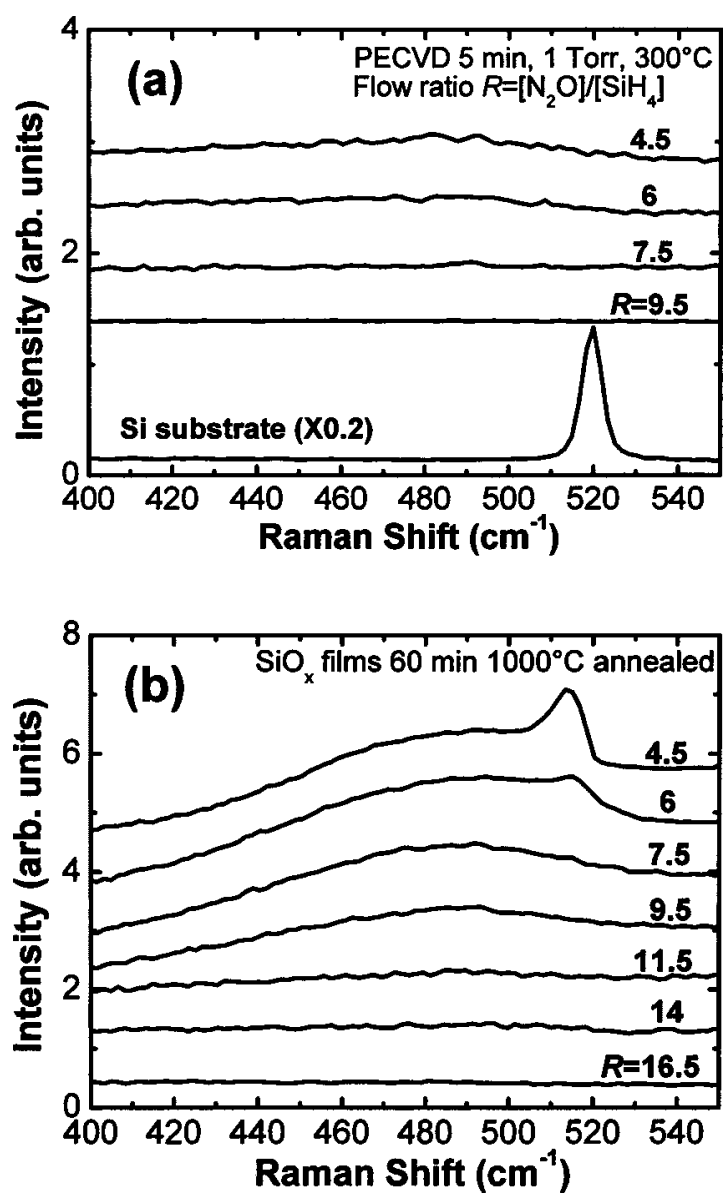

FIG. 3. Raman spectra of the $\mathrm{SiO}_{x}$ films deposited at different flow ratios of $R=\left[\mathrm{N}_{2} \mathrm{O}\right] /\left[\mathrm{SiH}_{4}\right]$ : (a) as-deposited and (b) after high-vacuum annealing for $60 \mathrm{~min}$ at $1000^{\circ} \mathrm{C}$.

difficult since the influence of the $a$-Si phase and the stresses in the films also need to be taken into account. The Raman peak will be redshifted and blueshifted by the tensile and compressive stresses, respectively.

\section{Film nanostructure}

The nanostructures of the $\mathrm{SiO}_{x}$ films were characterized by HRTEM. Due to the low contrast between $\mathrm{SiO}_{x}$ and $a$-Si, HRTEM can only reveal the presence of Si NCs by Si lattice planes. The as-deposited films show a uniform amorphous structure while no Si lattice planes corresponding to $c$-Si can be observed. The amorphous state of the as-deposited films agrees with the Raman results. After high-temperature annealing, $c$-Si NCs were formed in the film. The Si NCs are uniformly distributed along the film depth. Figures 4(a)-4(c) show the cross-sectional HRTEM images of the $\mathrm{SiO}_{x}$ films after high-vacuum annealing for $60 \mathrm{~min}$ at $1200{ }^{\circ} \mathrm{C}$. Figure 4(a) shows the image of the $\mathrm{SiO}_{x}$ film deposited at the flow ratio $R$ of 16.5. The lattice planes indicate the existence of very small $c$-Si NCs with sizes of $1-2 \mathrm{~nm}$. For the films deposited with the flow ratio $R$ higher than 16.5 , no $c$-Si NCs can be found. Figure 4(b) shows the image of the $\mathrm{SiO}_{x}$ film deposited at the flow ratio $R$ of 9.5. Si NCs with sizes of 2-6 $\mathrm{nm}$ were formed in the film. It is evident that some large NCs contain stacking faults. Figure 4(c) shows the image of the $\mathrm{SiO}_{x}$ film deposited at the flow ratio $R$ of 6 . Si NCs with sizes of 3-12 $\mathrm{nm}$ were formed in the film. The agglomeration of the Si NCs can also be observed. From Figs. 4(a)-4(c), the mean NC size increases from 1.5 to 3.6 and finally $6.3 \mathrm{~nm}$ with decreasing flow ratio $R$. The density of the Si NCs and the width of the NC size distribution also increase. Thus, at a certain annealing temperature, the NC size and density increase with increasing $\mathrm{Si}$ concentration, as the available nuclear site and excess $\mathrm{Si}$ in the films become more.

Figure 4(d) shows the $\mathrm{SiO}_{x}$ film deposited at the flow ratio $R$ of 6 after high-vacuum annealing for $60 \mathrm{~min}$ at $1000^{\circ} \mathrm{C}$. The (111) lattice planes suggest the existence of $c$-Si NCs even after annealing at $1000{ }^{\circ} \mathrm{C}$. On the other hand, no $c$-NCs can be found from the film annealed at $900{ }^{\circ} \mathrm{C}$. The mean $\mathrm{NC}$ size after annealing at $1000{ }^{\circ} \mathrm{C}$ is $3.4 \mathrm{~nm}$, which is smaller than that after $1200{ }^{\circ} \mathrm{C}$ annealing. The $\mathrm{Si}$ $\mathrm{NC}$ density is also lower than that after annealing at $1200^{\circ} \mathrm{C}$. Furthermore, Si NCs often have an elliptic shape at $1000^{\circ} \mathrm{C}$ while a spherical shape at $1200{ }^{\circ} \mathrm{C}$, suggesting the partial crystallization and the presence of amorphous material around $\mathrm{Si} \mathrm{NCs}$ at $1000^{\circ} \mathrm{C}$. With increasing temperature, the phase separation becomes stronger and the $a$-Si is also converted to the $c$-Si. Thus, both the size and density of the $\mathrm{Si}$ NCs increase with increasing annealing temperature. Both the progressive phase separation and $\mathrm{NC}$ formation are in good agreement with the observation from XPS and Raman investigations. Other authors ${ }^{9,10}$ also observed the increased NC size with increasing Si concentration and annealing temperature, which can be explained by a diffusion-controlled mechanism. ${ }^{17}$

\section{Optical absorption}

The optical absorption of the $\mathrm{SiO}_{x}$ films was characterized by UV-visible spectroscopy. The absorption coefficient $\alpha$ can be obtained through the following equation:

$$
T=\frac{\left(1-R_{f}\right)^{2} e^{-\alpha d}}{1-R_{f}^{2} e^{-2 \alpha d}},
$$

where $T$ is the transmittance measured from UV-visible, $d$ is the film thickness, and $R_{f}$ the reflection coefficient measured in the weak absorption range $(\lambda=1.3 \mu \mathrm{m})$. The optical band gap $E_{\text {opt }}$ can be estimated from the following relation which is known as Tauc plot:

$$
\alpha h \nu=\operatorname{const}\left(h \nu-E_{\mathrm{opt}}\right)^{n},
$$

where $h \nu$ is the photon energy and the exponent $n$ has the value of 2 for an indirect transition. In fact, the optical band gap $E_{\text {opt }}$ or Tauc gap of the amorphous semiconductor is determined from the extrapolation of the densities of states deeper in the bands ${ }^{18}$ or the electronic transition between extended states. ${ }^{19}$ Although $E_{\text {opt }}$ is always larger than the real band gap of the amorphous semiconductor, the difference between the $E_{\text {opt }}$ and the band gap will not obstruct our discussion based on the electronic structure of $a-\mathrm{SiO}_{x}$.

Figure 5(a) shows the Tauc plot, $(\alpha h \nu)^{1 / 2}$ as a function of $h \nu$ of the as-deposited $\mathrm{SiO}_{x}$ films. Approximately-linear relations are observed. Intersecting points of the horizontal axis correspond to the $E_{\text {opt }}$. The $E_{\text {opt }}$ of the as-deposited $\mathrm{SiO}_{x}$ films is blueshifted in comparison with that of the bulk $c$-Si 

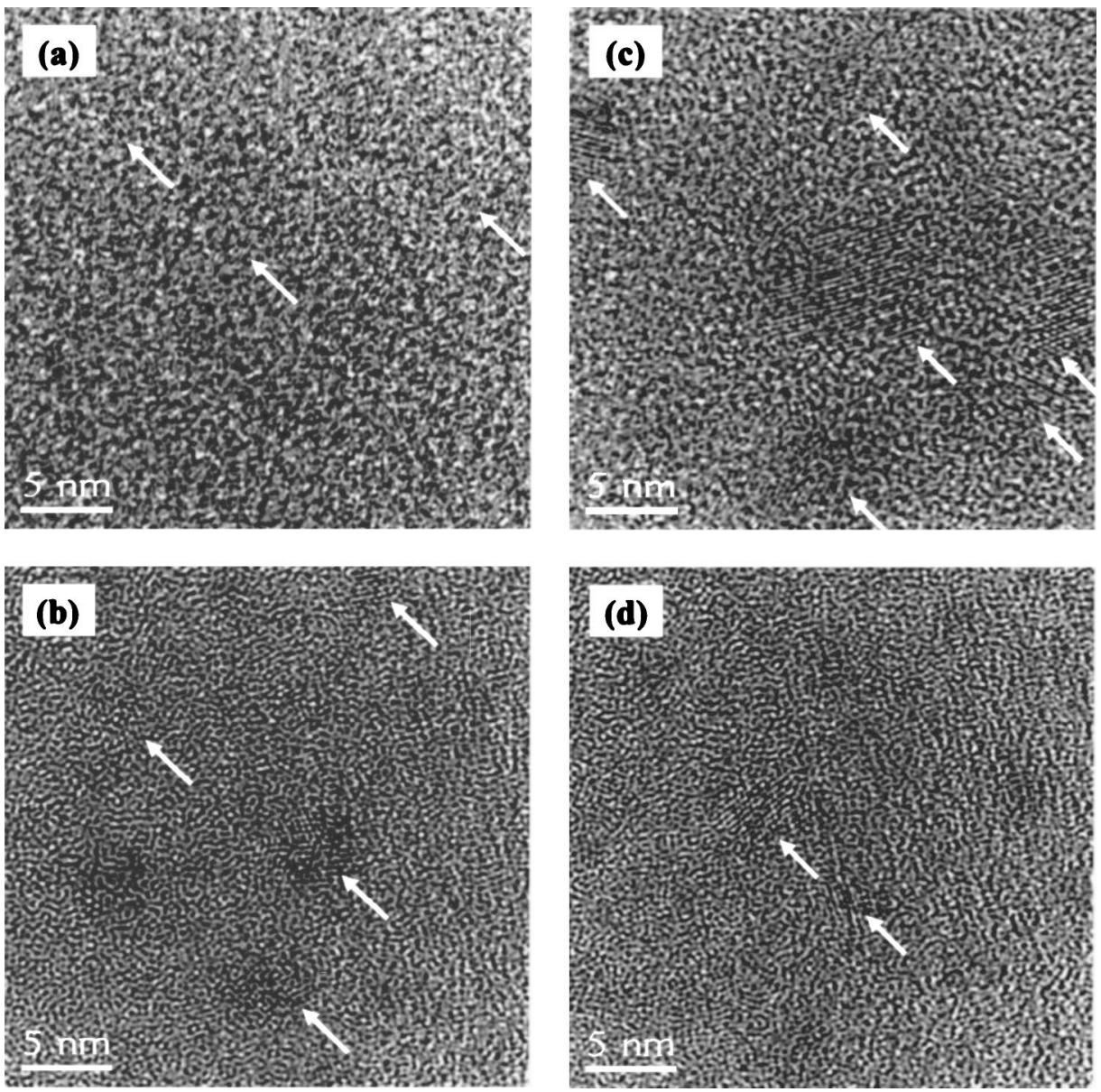

FIG. 4. Cross-sectional HRTEM images of the $\mathrm{SiO}_{x}$ films deposited at flow ratios $R$ of: (a) 16.5 , (b) 9.5 , and (c) 6 after high-vacuum annealing for 60 min at $1200{ }^{\circ} \mathrm{C}$. (d) Cross-sectional HRTEM image of the $\mathrm{SiO}_{x}$ film deposited at the flow ratio $R$ of 6 after highvacuum annealing for $60 \mathrm{~min}$ at $1000{ }^{\circ} \mathrm{C}$.
(1.12 eV), which suggests a band gap widening due to the quantum confinement effects (QCE). With decreasing flow ratio $R$ or increasing Si concentration in the films, the $E_{\text {opt }}$ is redshifted from 3.7 to $2.6 \mathrm{eV}$ on a continual basis and the absorption coefficient is enhanced with a steeper slope. According to the electronic structure of $a-\mathrm{SiO}_{x}$, the band gap of $a-\mathrm{SiO}_{2}$ is $\sim 8.5 \mathrm{eV}$ and that of $a-\mathrm{Si}$ is $\sim 1.5 \mathrm{eV}$. The electronic states of $a-\mathrm{SiO}_{2}$ near the valence band edge are derived from $\mathrm{O}$ nonbonding states. With $x$ decreases from 2.0 in $a-\mathrm{SiO}_{x}$, the valence band edge moves up, as the increased $\mathrm{Si}-\mathrm{Si}$ bond states are gradually overlaid with the $\mathrm{O}$ nonbonding states and finally spread out into the Si valence band. Simultaneously, the conduction edge also moves down. The net result is that the band gap decreases nonlinearly when $\mathrm{Si}$ concentration continually increases. ${ }^{13,20}$ The increased Sirelated clusters as diffuser centers also cause the enhancement of the absorption coefficient.

Figure 5(b) shows the Tauc plot of the as-deposited $\mathrm{SiO}_{x}$ films after annealing for $60 \mathrm{~min}$ at $1000{ }^{\circ} \mathrm{C}$. The $E_{\text {opt }}$ of the $1000{ }^{\circ} \mathrm{C}$ annealed films is redshifted to $2.2-3.0 \mathrm{eV}$ compared to that of the as-deposited films. The curve slope also becomes steeper. Indeed, the general trend of the optical absorption of the amorphous semiconductor is that a blue (red) shift can occur due to an ordering (disordering) reconstruction of the film network. ${ }^{21}$ Annealing to the amorphous semiconductor will result in both blueshift of the $E_{\mathrm{opt}}$ and steepening of the absorption edge at low energies due to the ordering of the films. In our case, however, obvious phase separation and $\mathrm{NC}$ formation occur in the $\mathrm{SiO}_{x}$ films at
$1000{ }^{\circ} \mathrm{C}$. The enhanced clustering of $\mathrm{Si}$ atoms increases the interaction between the $\mathrm{Si}-\mathrm{Si}$ bonds. The absorption of the films is dominated by the Si NCs which have a lower $E_{\text {opt }}$. Thus, instead of a blueshift, the $E_{\text {opt }}$ of the films shows a redshift after annealing.

\section{E. PL spectra}

Although the visible PL from Si nanostructures has been extensively studied for more than a decade, the physical mechanism of the PL is still under debate. Some work suggests that the light emission is due to the radiative recombination occurring in surface states or defect states localized at the surface of the Si core or extrinsic centers. ${ }^{22,23}$ The widely used QCE theory explains the highly efficient light emission as a result of the band-to-band radiative recombination of electron-hole pairs confined in Si NCs whose surfaces are very well passivated by $\mathrm{Si}-\mathrm{H}$ or $\mathrm{Si}-\mathrm{O}$ bond. ${ }^{24} \mathrm{QCE}$ occurs in a semiconductor when the physical dimension of the material approaches the size of its Bohr exciton radius. The confinement in real space (one-dimensional, two-dimensional, or three-dimensional) would, under Heisenberg's uncertainty principle, cause sufficient spreading of the wave function in momentum space for direct band-to-band recombination to occur. However, there is a quantitative discrepancy between the PL energy and the energy band gap calculated for $\mathrm{Si}$ NCs. ${ }^{4,25}$ The discrepancy has been explained using the "mixed" model, in which the recombination occurs via carriers trapped at intermediate states or localized states. The 

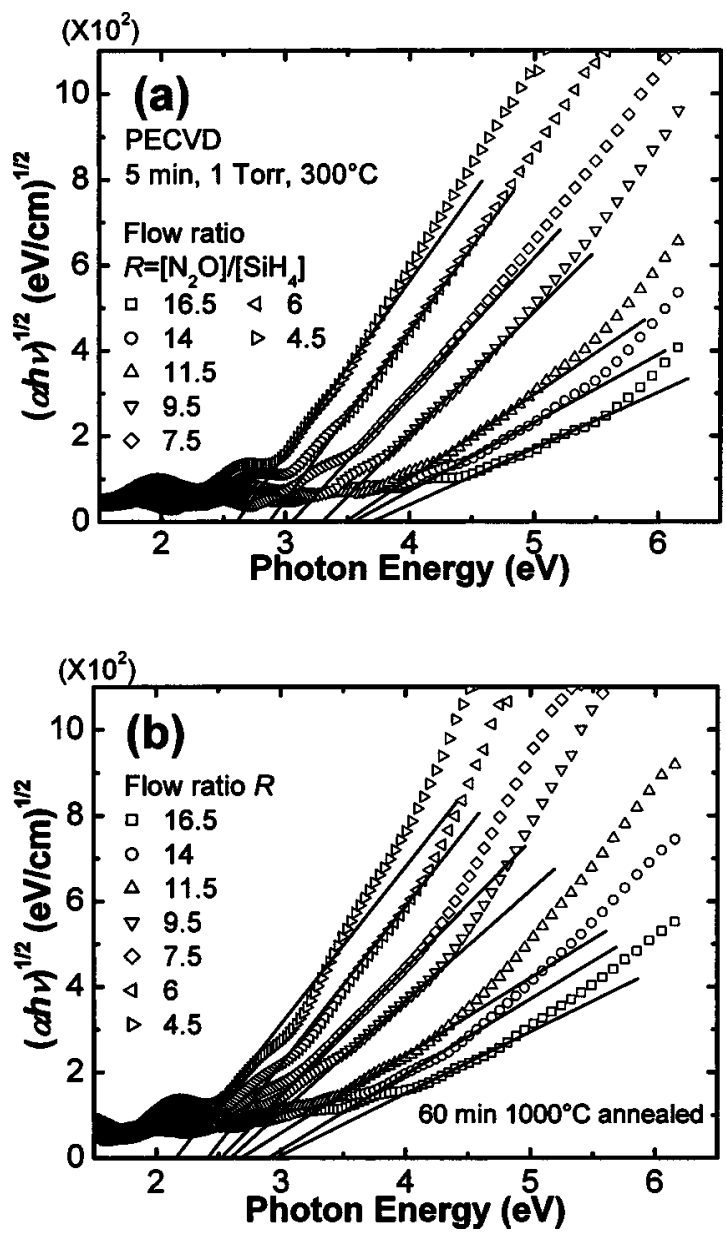

FIG. 5. Tauc plot, $(\alpha h \nu)^{1 / 2}$ vs $h \nu$ for the $\mathrm{SiO}_{x}$ films deposited at different flow ratios of $R=\left[\mathrm{N}_{2} \mathrm{O}\right] /\left[\mathrm{SiH}_{4}\right]$ : (a) as-deposited and (b) after high-vacuum annealing for $60 \mathrm{~min}$ at $1000{ }^{\circ} \mathrm{C}$

localized states appearing in the band gap are stabilized by the band gap widening induced by quantum confinement. ${ }^{4}$ The localized states, accompanying the enlarged band gap with decreasing NC size, can also explain the PL shifts with the NC size and the surface passivation.

The sensitive PL properties are greatly dependent on the preparation and postprocessing conditions. Some authors ${ }^{26}$ reported bright emission from as-deposited films, while other groups ${ }^{9,10}$ reported greatly enhanced PL after hightemperature annealing. Some works ${ }^{27,28}$ observed a blue/ green light emission while other studies ${ }^{9,29}$ reported that the PL is in the red range. The diverse or even contradictory experimental results in the literature suggest that the light emission from Si NCs has multiple mechanisms.

\section{UV-range $P L$}

The UV-range PL from the $\mathrm{SiO}_{x}$ films was studied using the $325 \mathrm{~nm} \mathrm{He}-\mathrm{Cd}$ laser line as excitation source. There is no UV-range PL from the as-deposited $\mathrm{SiO}_{x}$ films. After highvacuum annealing for $60 \mathrm{~min}$, a PL band at $\sim 380 \mathrm{~nm}(3.3$ eV) can be observed from the annealed films. Figure 6 shows the UV-range PL from the $\mathrm{SiO}_{x}$ films after annealing at $900{ }^{\circ} \mathrm{C}$. A broad PL band at $370-380 \mathrm{~nm}$ with a small shoulder at $\sim 490 \mathrm{~nm}$ is observed. The PL band is only apparent at the flow ratio $R$ ranging from 29 to 14 . The PL peak is fixed

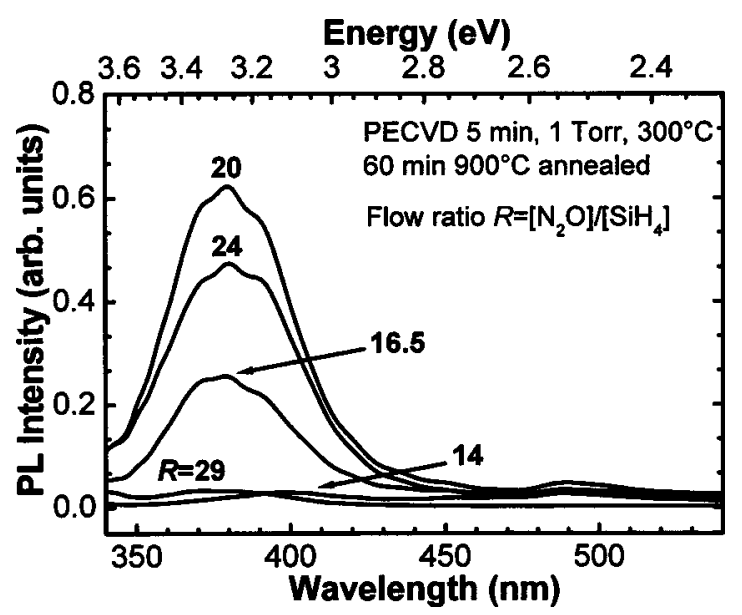

FIG. 6. UV-range PL from the $\mathrm{SiO}_{x}$ films after high-vacuum annealing for $60 \mathrm{~min}$ at $900^{\circ} \mathrm{C}$.

at $370-380 \mathrm{~nm}$ and independent of the flow ratio $R$ or the $\mathrm{Si}$ concentration in the films, which is a characteristic of defect states. With decreasing flow ratio $R$, the intensity of the PL increases first and then decreases. From XPS analysis, there is little or no elemental $\mathrm{Si}$ in the films when the flow ratio $R$ is above 14, which suggests that the PL is related to the defect states of the $\mathrm{SiO}_{2}$-like films. The $\mathrm{PL}$ at $3.3 \mathrm{eV}$ has been found in the $\mathrm{SiO}_{x}$ films formed by various methods such as PECVD, ${ }^{26}$ sputtering, ${ }^{30}$ and PLD. ${ }^{31}$ It is generally agreed that the PL at $3.3 \mathrm{eV}$ is attributed to the defect states related to $\mathrm{Si}-\mathrm{O}$ species in the $\mathrm{Si}$ suboxide. In the PS structure, the UV-range PL at $\sim 350 \mathrm{~nm}(3.5 \mathrm{eV})$ was also observed from oxidized layers and considered to arise from the defective oxide phase. ${ }^{32}$

The annealing temperature dependence of the PL at 3.3 $\mathrm{eV}$ was studied. The PL shows similar intensity evolution and fixed peak position at $370-380 \mathrm{~nm}$ at different annealing temperatures. Figure 7 presents the maximum peak intensity of the PL and maximum-peak-intensity-corresponded flow ratio $R$ as functions of the annealing temperature. It is found that the maximum PL intensity increases with increasing annealing temperature at low temperature range and decreases when the annealing temperature is higher than $900{ }^{\circ} \mathrm{C}$. When the annealing temperature increases, maximum-peak-

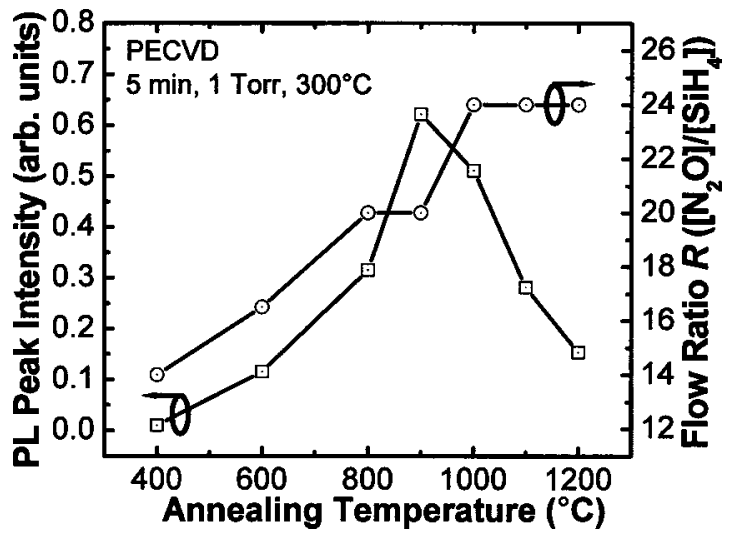

FIG. 7. Maximum peak intensity and maximum-peak-intensitycorresponded flow ratio $R$ of the UV-range PL as functions of the annealing temperature. 


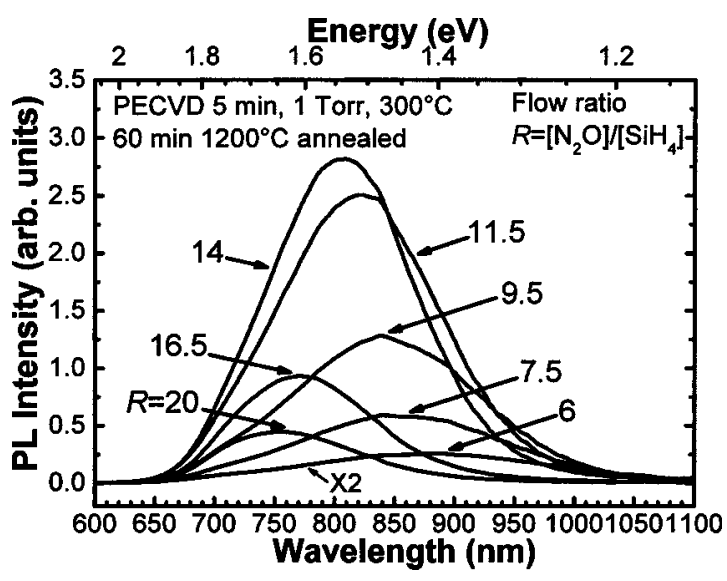

FIG. 8. Red-range PL from the $\mathrm{SiO}_{x}$ films after high-vacuum annealing for 60 min at $1200^{\circ} \mathrm{C}$

intensity-corresponded flow ratio $R$ also increases. As the phase separation of the $\mathrm{SiO}_{x}$ films starts at the temperature range of $400-700{ }^{\circ} \mathrm{C}$, the PL is not distinct after annealing at $400^{\circ} \mathrm{C}$. With increasing annealing temperature, the PL intensity increases due to the progressive phase separation. After annealing at temperatures higher than $900{ }^{\circ} \mathrm{C}$, the $\mathrm{Si}-\mathrm{O}$ species is not stable ${ }^{30}$ and obvious phase separation of $\mathrm{SiO}_{x}$ into more stable $\mathrm{Si}_{-} \mathrm{Si}_{4}$ and $\mathrm{Si}-\mathrm{O}_{4}$ tetrahedras takes place, resulting in the decrease of the PL intensity. Thus, the PL intensity evolution is closely related to the phase separation in the films. Furthermore, the increased annealing temperature will cause more phase separation in the films. As a result, the maximum PL intensity is obtained at higher flow ratio $R$ or lower $\mathrm{Si}$ concentration and the maximum-peak-intensitycorresponded flow ratio $R$ increases.

\section{Red-range $P L$}

The red-range $\mathrm{PL}$ from the $\mathrm{SiO}_{x}$ films was studied using the $532 \mathrm{~nm}$ line of Ar ion laser as an excitation source. The as-deposited films show weak PL at $650-700 \mathrm{~nm}$ when the flow ratio $R$ is in the low flow-ratio regime $L$, in which $a$-Si NCs may be formed directly during the deposition. After annealing at the temperature higher than $800{ }^{\circ} \mathrm{C}$, the PL from the films is completely quenched.

On the contrary, strong visible red PL was observed from the annealed films in the middle flow-ratio regime $M$ after high-vacuum annealing for $60 \mathrm{~min}$. Figure 8 shows the PL from the $\mathrm{SiO}_{x}$ films annealed at $1200{ }^{\circ} \mathrm{C}$. A PL band at $1.7-$ $1.4 \mathrm{eV}$ can be observed. The broad PL is fairly symmetric and can be fitted with a single Gaussian band. With decreasing flow ratio $R$, the PL is continuously redshifted from 1.7 to $1.4 \mathrm{eV}$. The PL intensity increases first and decreases when the flow ratio $R$ decreases from 14. From TEM measurements, the NC size continually increases with decreasing flow ratio $R$ or increasing Si concentration in the films. The decreasing PL peak energy with increasing NC size supports that the red PL is due to the QCE. Furthermore, the PL intensity is related to the density of small Si NCs in the films. When the flow ratio $R$ decreases from 14, the NC size becomes larger and high-density NCs tend to agglomerate together during the $\mathrm{NC}$ growth in the annealing. The reduction of small NCs causes a decrease of the PL intensity.
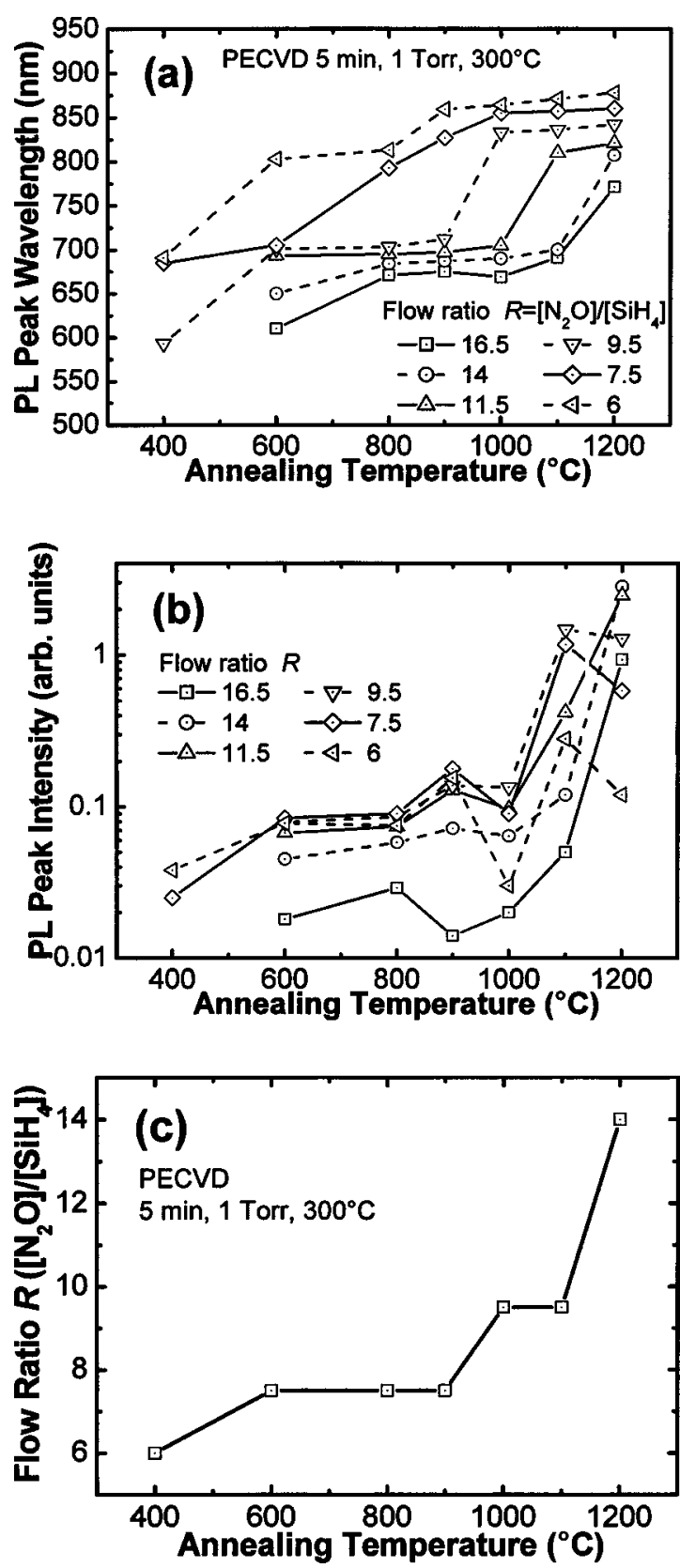

FIG. 9. Red-range PL dependence on the annealing temperature: (a) the PL peak wavelength, (b) the PL peak intensity, and (c) the maximum-PLintensity-corresponded flow ratio $R$ as functions of the annealing temperature.

The PL dependence on the annealing temperature was studied by varying the annealing temperature from 400 to $1200{ }^{\circ} \mathrm{C}$. Figure 9 shows the PL evolution as a function of the annealing temperature. The PL peak wavelength after annealing is summarized in Fig. 9(a). The PL peak varies from $\sim 600 \mathrm{~nm}(2.1 \mathrm{eV})$ to $900 \mathrm{~nm}(1.4 \mathrm{eV})$. The PL peak shows redshift with increasing Si concentration or Si NC size under a certain annealing temperature. Furthermore, the PL peak continually redshifts with increasing annealing temperature for a certain $\mathrm{SiO}_{x}$ film, as higher temperature causes more phase separation and growth of larger Si NCs. The redshift of PL with increasing Si concentration and annealing temperature, i.e., increasing $\mathrm{NC}$ size, is in good agreement with the QCE. 
The PL peak intensity after annealing is delineated in Fig. 9(b). The PL shows enhanced intensity after annealing. The PL intensity increases when the annealing temperature increases from 400 to $800{ }^{\circ} \mathrm{C}$ and reaches the maximum at $800-900{ }^{\circ} \mathrm{C}$. After annealing at $1000{ }^{\circ} \mathrm{C}$, the PL intensity decreases. Then the PL intensity shows a sharp increase of 1-2 orders when the annealing temperature increases from 1000 to $1200{ }^{\circ} \mathrm{C}$. The PL intensity evolution is in good agreement with the phase separation starting at $400-700{ }^{\circ} \mathrm{C}$ and the $\mathrm{NC}$ formation above $900{ }^{\circ} \mathrm{C}$. At the temperature below $900{ }^{\circ} \mathrm{C}$, the increase of the PL intensity is related to the phase separation of $a-\mathrm{SiO}_{x}$ and the decrease of dangling bonds or defects. At the temperature of $900-1000{ }^{\circ} \mathrm{C}$, the decrease of the PL intensity may be due to a structural change of existing $\mathrm{Si}$ clusters prior to their growth at higher temperatures. ${ }^{9}$ When the temperature increases from 1000 to $1200{ }^{\circ} \mathrm{C}$, the sharp increase of the PL intensity is due to the formation of $c$-Si NCs. At the temperature of $1200{ }^{\circ} \mathrm{C}$, the decrease of the PL intensity for the films deposited at the flow ratio $R$ lower than 9.5 (high $\mathrm{Si}$ concentration) is due to the agglomeration of $\mathrm{Si}$ $\mathrm{NCs}$ and reduction of small NCs.

The maximum-PL-intensity-corresponded flow ratio $R$ as a function of the annealing temperature is summarized in Fig. 9(c). It is evident that the maximum PL intensity is obtained at higher flow ratio $R$ or lower $\mathrm{Si}$ concentration with increasing annealing temperature, as the phase separation becomes stronger at higher temperature. Thus, the PL intensity evolution further supports that the light emission is due to the QCE.

It is noticed that the red-PL peak energies are much smaller than those predicted by theoretical calculation based on NC size from the QCE theory, especially the ones for the films with low Si concentration or small NC size. The discrepancy suggests that our data agrees with the mixed model. The recombination occurs via carriers trapped at oxygenrelated localized states.

In summary, we have observed two PL bands. The UVrange PL is independent of Si concentration and annealing temperature, which is a characteristic of defect states. The red-range PL shows good agreement between the phase separation/NC formation and the PL peak shift/intensity change, which can be explained by the QCE. Several authors ${ }^{26,33,34}$ also described two PL bands in blue-green and yellow-red ranges from $\mathrm{SiO}_{x}$. They attributed the blue-green band to the carrier recombination at defects and the yellowred band to the recombination of confined electron-hole pairs in Si NCs, which is consistent to our results.

\section{F. Oxidation effects}

Dry oxidation was applied to the as-deposited $\mathrm{SiO}_{x}$ films. Figure 10 shows the red-range PL from the asdeposited $\mathrm{SiO}_{x}$ films after oxidation for $60 \mathrm{~min}$ at $1200{ }^{\circ} \mathrm{C}$. A strong red PL is observed. The PL peak positions are blueshifted compared with those of the as-deposited $\mathrm{SiO}_{x}$ films after annealing at $1200{ }^{\circ} \mathrm{C}$. The PL intensities vary slightly from those after annealing at $1200{ }^{\circ} \mathrm{C}$. Thus, luminescent $\mathrm{SiO}_{x}$ films can also be formed directly by oxidation. During oxidation, phase separation by annealing and oxidation by

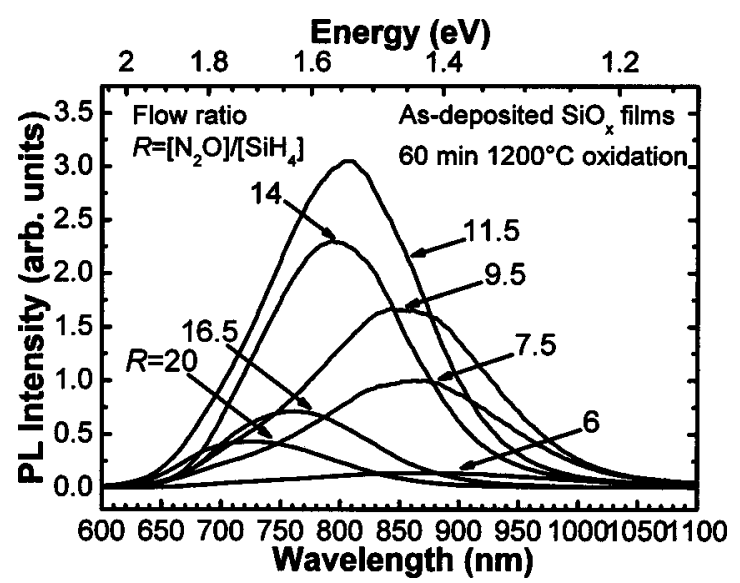

FIG. 10. Red-range PL from the as-deposited $\mathrm{SiO}_{x}$ films after dry oxidation for $60 \mathrm{~min}$ at $1200{ }^{\circ} \mathrm{C}$.

oxygen diffusion through the oxide compete with each other. Fernandez et al $^{35}$ reported that Si NCs have already been formed after 1 min rapid thermal annealing (RTA) and almost imperceptible size growth was observed in the subsequent annealing. On the other hand, oxidation for the bulk Si occurs at the $\mathrm{Si} / \mathrm{SiO}_{2}$ interface which moves into the bulk Si. Oxidation of bulk $\mathrm{Si}$ at $1200{ }^{\circ} \mathrm{C}$ for $60 \mathrm{~min}$ will produce a $\mathrm{SiO}_{2}$ layer of $\sim 200 \mathrm{~nm} .{ }^{36}$ Furthermore, oxidation of Si NCs is a well known self-limiting process. ${ }^{37}$ The stress in the oxide layer that confines the Si NCs can suppress the oxidation of the Si NCs, leading to decreased oxidation rate with decreasing NC size. The oxidation rate is reduced to $1 / 3$ for $\mathrm{Si} \mathrm{NC}$ with an initial size of $15 \mathrm{~nm}$ compared with that of $\mathrm{Si}(100)$ substrate for $15 \mathrm{~h}$ oxidation at $750{ }^{\circ} \mathrm{C} .{ }^{38}$ As oxidation is much slower than RTA, oxidation of the as-deposited $\mathrm{SiO}_{x}$ films can be regarded as a two-step process, i.e., a RTA process finished in $1 \mathrm{~min}$, and a dominant long-time oxidation subsequently. Thus, oxidation of the as-deposited $\mathrm{SiO}_{x}$ films is analogical to oxidation of the annealed $\mathrm{SiO}_{x}$ films.

To further study the oxidation effects, dry oxidation was applied to the high-temperature annealed $\mathrm{SiO}_{x}$ films. As $\mathrm{Si}$ NCs have been formed by high-temperature annealing, oxidation reduces the $\mathrm{NC}$ size and converts the outer layer of $\mathrm{NC}$ into Si oxide. Figure 11 shows the red-range PL from the $1200{ }^{\circ} \mathrm{C}$ annealed $\mathrm{SiO}_{x}$ films after oxidation for $60 \mathrm{~min}$ at

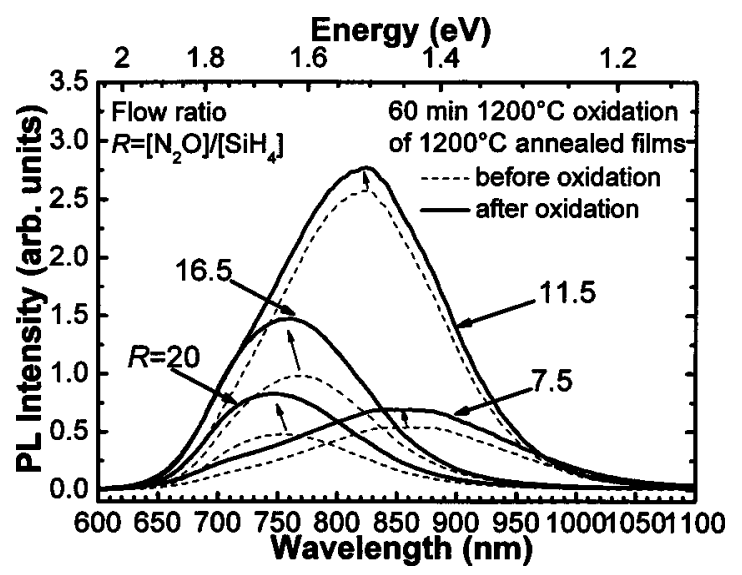

FIG. 11. Red-range PL from $\mathrm{SiO}_{x}$ films after $1200{ }^{\circ} \mathrm{C}$ annealing and subsequent dry oxidation for $60 \mathrm{~min}$ at $1200^{\circ} \mathrm{C}$. 


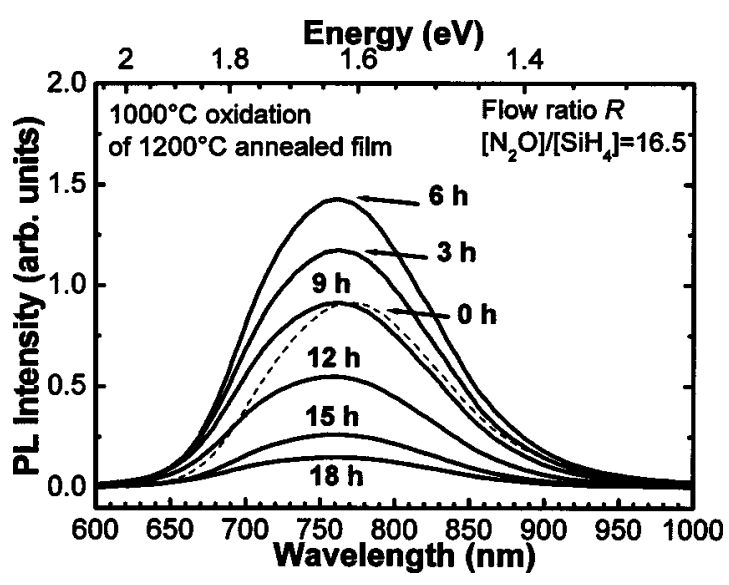

FIG. 12. Red-range PL from the $\mathrm{SiO}_{x}$ film deposited at the flow ratio $R$ of 16.5 after $1200{ }^{\circ} \mathrm{C}$ annealing and subsequent dry oxidation at $1000{ }^{\circ} \mathrm{C}$.

$1200{ }^{\circ} \mathrm{C}$. The PL spectra from the as-annealed $\mathrm{SiO}_{x}$ films are shown for reference using dash-line curves. The PL is blueshifted after oxidation. The blueshift is more evident at the flow ratio $R$ of 20 and 16.5. With decreasing flow ratio $R$, the blueshift becomes smaller. The blueshift of the PL is attributed to the QCE. As the NC size decreases after oxidation, the band gap of Si NCs increases. The emission at shorter wavelengths results in the blueshift of the PL. The reduced blueshift with decreasing flow ratio $R$ indicates that the $\mathrm{Si}$ NCs with a higher density and bigger size experience a slower oxidation. The slower oxidation may be due to the limited oxygen diffusion or higher stress induced by Si oxide which covers the Si NCs.

In Fig. 11, the PL intensity is enhanced after $60 \mathrm{~min}$ oxidation. As Si NCs were formed and embedded in the $\mathrm{Si}$ oxide matrix after annealing, there is an intermediate or interfacial layer between the Si NCs and the Si oxide matrix. The nonstoichiometric Si oxide matrix and interfacial layer, which are still a suboxide with high-density defects, cause the nonradiative decay of the quantum-confined excitons. The oxidation can convert the Si oxide matrix and interfacial layer into stoichiometric $\mathrm{SiO}_{2}$, resulting in the decrease of the nonradiative decay channels. As a result, the PL intensity increases after oxidation. We also studied the UV-range PL after oxidation for $60 \mathrm{~min}$ at $1200{ }^{\circ} \mathrm{C}$. It is found that the UV-range PL at 370-380 nm has been almost quenched. It means that the $\mathrm{Si}-\mathrm{O}$ structures in the $\mathrm{Si}$ suboxide responsible for the PL have been destroyed, which further confirms the conversion of the $\mathrm{Si}$ oxide matrix and interfacial layer into stoichiometric $\mathrm{SiO}_{2}$.

Continuous dry oxidation at $1000{ }^{\circ} \mathrm{C}$ was applied to the $1200{ }^{\circ} \mathrm{C}$ annealed $\mathrm{SiO}_{x}$ film deposited at the flow ratio $R$ of 16.5. Figure 12 shows the PL spectra evolution after continuous oxidation. The PL peak is blueshifted from $\sim 770$ to 750 $\mathrm{nm}$ with increasing oxidation time, as the average size of $\mathrm{Si}$ NCs decreases. The PL intensity increases after $6 \mathrm{~h}$ oxidation and then decreases for longer oxidation times. The decrease of the PL intensity for long oxidation is because the number of Si NCs decreases with increasing oxidation time. The oxidation rate for bulk $\mathrm{Si}$ was also calculated using the well known mixed linear-parabolic equation from the Deal and Grove model. ${ }^{36}$ The $\mathrm{SiO}_{2}$ thickness is $\sim 390 \mathrm{~nm}$ after $18 \mathrm{~h}$ oxidation at $1000{ }^{\circ} \mathrm{C}$ for bulk $\mathrm{Si}$. As the thickness of the as-deposited $\mathrm{SiO}_{x}$ film is $\sim 540 \mathrm{~nm}$, most part of the film is considered to have been oxidized and thus the PL intensity decreases. The blueshift of the PL with increasing oxidation time was also observed by Brongersma et al. ${ }^{39}$ for Si NCs formed by ion implantation. They reported a continuous blueshift of more than $200 \mathrm{~nm}$ for the PL peak due to the QCE. Our blueshift of $\sim 20 \mathrm{~nm}$ is much smaller, which indicates the role of localized states for the PL.

\section{CONCLUSIONS}

The physical and optical properties of $\mathrm{SiO}_{x}$ films fabricated by PECVD were studied by high-vacuum annealing and thermal oxidation. The $\mathrm{Si}$ concentration in the asdeposited films increases with decreasing $\mathrm{N}_{2} \mathrm{O} / \mathrm{SiH}_{4}$ flow ratio. The as-deposited films have a random-bonding or continuous-random-network structure with large amount of suboxide. After high-temperature (above $1000^{\circ} \mathrm{C}$ ) annealing, the intermediate suboxide showed a transformation to $\mathrm{SiO}_{2}$ and elemental Si. Raman, HRTEM, and optical absorption confirmed the phase separation and the formation of Si NCs in the films. The Si NC size was found to increase with increasing $\mathrm{Si}$ concentration and annealing temperature. Two PL bands were observed in the as-deposited films after annealing. The UV-range PL with peak fixed at $370-380 \mathrm{~nm}$ is independent of Si concentration and annealing temperature. The strong red-range PL showed redshifts with increasing $\mathrm{Si}$ concentration and annealing temperature, i.e., increasing $\mathrm{NC}$ size. After post-annealing oxidation, the UV PL was almost quenched due to the destruction of defect states while the red PL showed continuous blueshifts with increasing oxidation time due to the decreasing NC size. The distinct annealing and oxidation behaviors related the UV PL to the defect state mechanism and the red PL to the recombination of quantumconfined excitions.

\section{ACKNOWLEDGMENTS}

The authors are grateful to N. B. R. Hairul and H. L. Koh for the technical support.

${ }^{1}$ S. Furukawa and T. Miyasato, Jpn. J. Appl. Phys., Part 2, Part 2 27, L2207 (1988).

${ }^{2}$ H. Takagi, H. Ogawa, Y. Yamazaki, A. Ishizaki, and T. Nakagiri, Appl. Phys. Lett. 56, 2379 (1990).

${ }^{3}$ L. T. Canham, Appl. Phys. Lett. 57, 1046 (1990).

${ }^{4}$ M. V. Wolkin, J. Jorne, P. M. Fauchet, G. Allan, and C. Delerue, Phys. Rev. Lett. 82, 197 (1999).

${ }^{5}$ T. S. Iwayama, S. Nakao, and K. Saitoh, Appl. Phys. Lett. 65, 1814 (1994).

${ }^{6}$ Q. Zhang, S. C. Bayliss, and D. A. Hutt, Appl. Phys. Lett. 66, 1977 (1995).

${ }^{7}$ U. Kahler and H. Hofmeister, Appl. Phys. Lett. 75, 641 (1999).

${ }^{8}$ T. Makimura, Y. Kunii, N. Ono, and K. Murakami, Jpn. J. Appl. Phys., Part 2 35, L1703 (1996).

${ }^{9}$ T. Inokuma, Y. Wakayama, T. Muramoto, R. Aoki, Y. Kurata, and S. Hasegawa, J. Appl. Phys. 83, 2228 (1998).

${ }^{10}$ F. Iacona, G. Franzò, and C. Spinella, J. Appl. Phys. 87, 1295 (2000).

${ }^{11}$ B. J. Hinds, F. Wang, D. M. Wolfe, C. L. Hinkle, and G. Lucovski, J. Vac. Sci. Technol. B 16, 2171 (1998).

${ }^{12}$ D. Nesheva, C. Raptis, A. Perakis, I. Bineva, Z. Aneva, Z. Levi, S. Alexandrova, and H. Hofmeister, J. Appl. Phys. 92, 4678 (2002).

${ }^{13}$ F. G. Bell and L. Ley, Phys. Rev. B 37, 8383 (1988).

${ }^{14}$ S. Hayashi, S. Tanimoto, and K. Yamanoto, J. Appl. Phys. 68, 5300 
(1990).

${ }^{15}$ B. H. Augustine, E. A. Irene, Y. J. He, K. J. Price, L. E. McNeil, K. N. Christensen, and D. M. Maher, J. Appl. Phys. 78, 4020 (1995).

${ }^{16}$ T. I. Campbell and P. Fauchet, Solid State Commun. 58, 739 (1986).

${ }^{17}$ L. A. Nesbit, Appl. Phys. Lett. 46, 38 (1985).

${ }^{18}$ J. Tauc, Amorphous and Liquid Semiconductors (Plenum, London, 1974), p. 159.

${ }^{19}$ M. H. Brodsky, Solid State Commun. 36, 55 (1980).

${ }^{20}$ A. I. Bennett and L. M. Roth, Phys. Rev. B 4, 2686 (1971).

${ }^{21}$ G. D. Cody, in Semiconductors and Semimetals, edited by J. I. Pankove (Academic, New York, 1984), Vol. 21B, p. 11.

${ }^{22}$ F. Koch, V. Petrova-Koch, and T. Muschik, J. Lumin. 57, 271 (1993).

${ }^{23}$ S. M. Prokes, Appl. Phys. Lett. 62, 3244 (1993).

${ }^{24}$ B. Delley and E. F. Steigmeier, Phys. Rev. B 47, 1397 (1993).

${ }^{25}$ L. N. Dinh, L. L. Chase, M. Balooch, W. J. Siekhaus, and F. Wooten, Phys. Rev. B 54, 5029 (1996).

${ }^{26}$ S. Tong, X.-N. Liu, T. Gao, and X.-M. Bao, Appl. Phys. Lett. 71, 698 (1997).

${ }^{27}$ L. Patrone, D. Nelson, V. I. Safarov, M. Sentis, and W. Marine, J. Appl. Phys. 87, 3829 (2000).

${ }^{28}$ O. Hanaizumi, K. Ono, and Y. Ogama, Appl. Phys. Lett. 82, 538 (2003).
${ }^{29}$ Z. X. Ma, X. B. Liao, W. C. Cheng, G. Z. Yue, Y. Q. Wang, and G. L. Kong, J. Appl. Phys. 83, 7934 (1998).

${ }^{30}$ H. Z. Song, X. M. Bao, N. S. Li, and X. L. Wu, Appl. Phys. Lett. 72, 356 (1998).

${ }^{31}$ D. B. Geohegan, A. A. Puretzky, G. Duscher, and S. J. Pennycook, Appl. Phys. Lett. 72, 2987 (1998).

${ }^{32}$ A. G. Cullis, L. T. Canham, and P. D. J. Calcott, J. Appl. Phys. 82, 909 (1997).

${ }^{33}$ A. J. Kenyon, P. F. Trwoga, C. W. Pitt, and G. Rehm, J. Appl. Phys. 79, 9291 (1996).

${ }^{34}$ L. Khomenkova et al., J. Lumin. 102-103, 705 (2003).

${ }^{35}$ B. G. Fernandez, M. López, C. García, A. Pérez-Rodríguez, J. R. Morante, C. Bonafos, M. Carrada, and A. Claverie, J. Appl. Phys. 91, 798 (2002).

${ }^{36}$ L. E. Katz, in VLSI Technology, edited by S. M. Sze (McGraw-Hill, New York, 1988), p. 99.

${ }^{37}$ D. B. Kao, J. P. McVittie, W. D. Nix, and K. C. Saraswat, IEEE Trans. Electron Devices 35, 25 (1988).

${ }^{38}$ J. Omachi, R. Nakamura, K. Nishiguchi, and S. Oda, Mater. Res. Soc. Symp. Proc. 638, F531 (2001).

${ }^{39}$ M. L. Brogersma, A. Polman, K. S. Min, E. Boer, T. Tambo, and H. A. Atwater, Appl. Phys. Lett. 72, 2577 (1998). 